\title{
Factors Determining the Success of Therapeutic Lifestyle Interventions in Diabetes - Role of Partner and Family Support
}

\author{
Lovely Gupta, ${ }^{1}$ Deepak Khandelwal, ${ }^{2}$ Priti Rishi Lal, ${ }^{1}$ Yasheep Gupta, ${ }^{3}$ Sanjay Kalra, ${ }^{4}$ Deep Dutta ${ }^{5}$
}

1. Department of Food and Nutrition, Lady Irwin College, University of Delhi, New Delhi, India; 2. Maharaj Agrasen Hopsital, Punjabi Bagh, New Delhi, India; 3. Department of Endocrinology, All India Institute of Medical Sciences, New Delhi, India; 4. Department of Endocrinology, Bharti Hospitals, Karnal, Haryana, India; 5. Department of Endocrinology, Diabetes \& Metabolic Disorders, Venkateshwar Hospitals, New Delhi, India

$\mathrm{B}$ ackground and aims: Knowledge of therapeutic lifestyle interventions is one of the most important pillars of diabetes care; however, its incorporation in real-world settings is poor. This review evaluates the role of partner and family support in diabetes management. Methods: Literature searches were performed in PubMed, Medline and Embase for articles published before July 2018, using the terms "therapeutic lifestyle intervention" [MeSH Terms], OR "diet changes" [All Fields], OR "spousal participation" [All Fields], OR "lifestyle interventions" [All Fields], "lifestyle changes" [All Fields] AND "diabetes" [All Fields]. The search was not restricted to Englishlanguage literature; literature in Spanish, French and German were also evaluated. Results: A total of 66 of articles were reviewed, which included 33 original work, 21 review articles, and 12 systematic reviews and meta-analyses. Studies and meta-analyses have showed that if one partner has type-2 diabetes this increases the risk in other by 5-26\%. Partner and family have similar diet, lifestyle, and micro- and macro-environments which could explain the similar increased risk of diabetes and non-communicable diseases. Studies have consistently shown that spousal and family support plays a key role in overcoming negative behaviours and optimising behaviours in diabetes control. Partner support has major role in prevention and control of diabetes distress, associated depression, and medication non-compliance which have an adverse impact in glycaemic outcomes. These data are predominantly available from observational studies. There is paucity of data from interventional trials evaluating effects of family and spousal participation on health, glycaemic control and quality of life. Conclusion: The support of family and spouse/partner is beneficial to improve adherence to the lifestyle interventions and pharmacotherapy required to achieve optimum glycaemic control and avoid associated complications.

\section{Keywords}

Diabetes, partner participation, relationships, challenges, lifestyle management

Disclosures: Lovely Gupta, Deepak Khandelwal, Priti Rishi Lal, Yasheep Gupta, Sanjay Kalra and Deep Dutta have no conflicts of interest to declare in relation to this article.

Review Process: Double-blind peer review. Compliance with Ethics: This article involves a review of the literature and did not involve any studies with human or animal subjects performed by any of the authors.

Authorship: All named authors meet the criteria of the International Committee of Medical Journal Editors for authorship for this manuscript, take responsibility for the integrity of the work as a whole and have given final approval for the version to be published.

Received: 19 May 2018

Accepted: 31 October 2018

Citation: European Endocrinology. 2019;15(1):18-24

Corresponding Author: Deep Dutta, Department

of Endocrinology, Diabetes \& Metabolic Disorders,

Venkateshwar Hospitals, Sector 18A Dwarka,

New Delhi, India 110075

E: deepdutta2000@yahoo.com;

ORCID ID: 0000-0003-4915-8805

Support: No funding was received in

the publication of this article.
Type 2 diabetes mellitus (T2DM) is a chronic disease characterised by hyperglycaemia and compounded by insufficient production of insulin (beta cell dysfunction) to overcome the ineffective action of insulin (insulin resistance). According to International Diabetes Federation Eighth Atlas (2017), there were 425 million diabetic people (20-79 years of age) worldwide. ${ }^{1}$ The number of people affected by diabetes is expected to reach 629 million by 2045. ${ }^{1}$ Unique challenges with diabetes in India include the high prevalence of the disease ( $9 \%$ for diabetes and $12-15 \%$ for prediabetes), nearly 2 decade earlier onset of T2DM among Indians, as compared to the rest of the world, a more aggressive disease phenotype (highest rates of prediabetes progression to diabetes of $18 \%$ per annum), increasing problem of obesity, and primarily effecting the economically productive population (age 18-60 years) of the society. ${ }^{2,3}$

Optimal and appropriate diet, calorie restriction, physical activity and medication adherence are four key pillars of therapeutic lifestyle interventions in the management of diabetes. ${ }^{4,5}$ In spite of awareness, poor compliance to therapeutic lifestyle interventions contributes to poor glycaemic control and increased end-organ damage resulting in poor quality of life in the long run. This perpetuates a viscous cycle of poor control and further complications, which at times, becomes difficult a difficult cycle for the patient to break. ${ }^{6}$ The important factors which contribute to medication non-adherence are knowledge and perception of disease, complexity of dosing regimen and difficulty in managing complex treatment regimens or their side effects, financial constraints, psychological factors, and lack of social support. . $^{5-7}$

Family support and social relationships, as a part of individual treatment and healthcare, are beneficial for better glycaemic control and improved quality of life.? Health-related behaviour change interventions influence healthier lifestyles among people with diabetes but the effectiveness and sustainability is low..$^{8,9}$ The role of family support and especially the spousal relationship is an important component outside of the social networks, as the partner spends a considerable portion of his or her life in the shared environment. Joint management efforts with spousal participation are hypothesised to produce effective and sustainable results in diabetes management. ${ }^{10,11}$ Hence the aim of this review is to analyse the literature to develop better 
insights regarding successful implementation of lifestyle intervention programmes in diabetes. There is a special focus on evaluating the role of family and partner support in successful implementation of therapeutic lifestyle programmes.

\section{Methods}

A literature search was performed in PubMed, Medline and Embase for articles published before July 2018 , using the terms "therapeutic lifestyle intervention" [MeSH Terms], OR "diet changes" [All Fields], OR "spousal participation" [All Fields], OR "lifestyle interventions" [All Fields], "lifestyle changes" [All Fields] AND "diabetes" [All Fields]. The reference lists of the articles identified were also searched. The search was not restricted to English-language literature; literature in Spanish, French and German were also evaluated.

\section{Results}

A total of 66 articles were reviewed, which included 33 original work, 21 review articles and 12 systematic reviews and meta-analysis. The key information obtained from these articles has been elaborated below.

\section{Effectiveness of lifestyle interventions in people with type 2 diabetes mellitus}

Lifestyle intervention such as proper diet and physical activity, can improve glycaemic control and other metabolic risk factors, which in turn, has the potential to prevent diabetic complications. Huang et al. conducted a systematic review and meta-analysis of 17 randomised clinical trials comparing lifestyle intervention with "usual care" (control) in patients with T2DM and found that dietary intervention showed an improvement in glycated haemoglobin (HbA1C), systolic/diastolic blood pressure and high-density lipoprotein (HDL) cholesterol, suggesting that nutritional intervention had a significant impact on different components of metabolic syndrome, and hence has a potential to reduce cardiovascular risk in T2DM. ${ }^{12}$

Cezaretto et al. conducted a systematic review and meta-analysis of randomised controlled trials found a significant reduction in depression scores following lifestyle interventions in the pooled analysis (standardised mean difference [SMD] -0.165; 95\% confidence interval [CI] -0.265, -0.064; I[2] 67.9\%) and when limited to individuals with T2DM (SMD -0.202; 95\% $\mathrm{Cl}-0.288,-0.079$; I[2] 72.5\%). ${ }^{13}$ Htoo et al. found that Southeast Asian adults with diabetes who received lifestyle modifications for 3 months had statistically significant reductions in $\mathrm{HbA} 1 \mathrm{C}$, compared to the control group. ${ }^{14}$ However, the effects tended to blunt out after 6 months of follow up (i.e., non-significant reduction in $\mathrm{HbA} 1 \mathrm{c}$ in the intervention group compared to the control group beyond 6 months follow up). . $1,15^{-10 n}$

The above data provides evidence to support the role of therapeutic lifestyle interventions in improving glycaemia and other complications associated with diabetes. They can also be effective for other associated features such as depression. However, evidence for long-term sustainability beyond 6 months, especially in Asians, needs to be further assessed in people with diabetes. ${ }^{16}$ It may be hypothesised that poor compliance to therapeutic lifestyle interventions beyond 6 months may contribute to its decreased efficacy over long periods of time

\section{Real-world challenges to the implementation of therapeutic lifestyle interventions Adherence to treatment}

Low compliance to prescribed treatment approaches is a common problem in patients with chronic diseases. ${ }^{17,18} \mathrm{~A}$ meta-analysis published in 2018 (including 2,491 screened records and 24 studies on 369,251 people from 20 countries) reported that target achievement rates for glycaemic control were $42.8 \%$ (95\% Cl 38.1-47.5\%). ${ }^{19}$ The World Health Organization (WHO) has reported that approximately $50 \%$ of patients with a chronic illness are non-adherent with their treatment regimen (diet, activity, monitoring and medications); the rate is even higher in developing countries. ${ }^{20} \mathrm{~A}$ review article published in 2014 focusing on qualitative research, meta-syntheses, and meta-ethnography articles estimated more than $40 \%$ non-adherence to treatment and medical recommendations among patients with T2DM. ${ }^{21}$

The factors associated with such non-adherence could be patient related, such as understanding of the disease, coping mechanisms, motivation for control; family related factors, such as social or financial support; treatment related, such as simplicity and effectiveness of regimen; or healthcare related, for example easy accessibility to competent doctors and relationship with healthcare professionals. ${ }^{22-25}$ Evidence-based research should explore further possible factors, their operational mechanisms and possible solutions (as summarised in Tables 1 and 2) to overcome non-adherence and improve glycaemic management. ${ }^{26-30}$ The pragmatic understanding of the various reasons of non-adherence, changes in attitude and motivation along with intensive treatment and lifestyle interventions in group setting are evidenced to improve adherence to the lifestyle recommendations and glycaemic outcomes. ${ }^{31}$ Overcoming these factors with a multifaceted approach can help in achieving good treatment outcomes, with improvement in quality of life for patients.

Given the challenges of non-adherence, family involvement can be greatly beneficial in therapeutic lifestyle programmes, as seen in Figure $1^{23,25,26,29,30}$

\section{Diabetes distress}

Clinical depression and diabetes distress are prevalent emotional states found among people with diabetes, which can significantly affect the glycaemic control; lower blood glucose monitoring frequency; and increase micro-vascular complications, healthcare use and expenditures. ${ }^{32}$ Lack of social support is determined to be a major risk factor for diabetes distress, and social stigma often prevents discussing or seeking help for psychological problems. ${ }^{33}$ Positive spousal support in T2DM intervention programmes has been evidenced as a moderator between psychological morbidity to promote adherence to treatment therapies, patient satisfaction with healthcare services, and compliance to therapeutic lifestyle interventions. ${ }^{34}$

\section{Exploring family-based approach to cope with real- world challenges}

It has been shown that family participation can improve the effectiveness of lifestyle interventions for enhancing diabetes self-management. People eat and enjoy meals together in routine and rituals with family members which influence dietary patterns; consistent bad dietary habits can have adverse health potentials. ${ }^{35}$ On the other hand, any cumbersome dietary changes which are difficult to accept, in society or by the people they live with, can ultimately lead to non-adherence or non-compliance. Contextually, a study conducted in 2017 assessed interconnected problem domains (knowledge, communication, support, everyday life, roles and worries) to understand how family involvement can be supported in healthcare practices. ${ }^{36}$ Similarly, a systematic review conducted in 2017, identified the behavioural influence (in terms of facilitators, barriers or equivocal behaviours) affecting an individual's diabetes self-management. ${ }^{37}$ The important themes that emerged from these, and other studies in this context, are described as follows: 
Table 1: Factors affecting treatment adherence and strategies to overcome these

\begin{tabular}{|c|c|}
\hline Possible factors & Possible solutions \\
\hline \multicolumn{2}{|l|}{ Personal factors } \\
\hline $\begin{array}{l}\text { - } \text { Poor literacy } \\
\text { - } \quad \text { Lack of knowledge about diabetes and associated comorbidities } \\
\text { - } \text { Time pressure or forgetfulness } \\
\text { - Low level of disease/treatment acceptance } \\
\text { - } \quad \text { Lack of healthy coping skills }\end{array}$ & 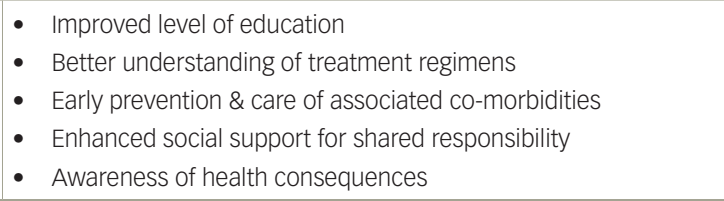 \\
\hline \multicolumn{2}{|l|}{ Economic factors } \\
\hline - Financial constraints & $\begin{array}{l}\text { - } \quad \text { Financial support from family members } \\
\text { - } \quad \text { Affordable access to healthcare facilities }\end{array}$ \\
\hline \multicolumn{2}{|l|}{ Social factors } \\
\hline $\begin{array}{l}\text { - Lack of family, peer and community support } \\
\text { - } \quad \text { Limited spousal support/divorce } \\
\text { - } \quad \text { Uncomfortable facing social gatherings and social stigma } \\
\text { - } \quad \text { Appropriate health beliefs: cultural and religious } \\
\text { - Ethnic minority }\end{array}$ & $\begin{array}{l}\text { - } \quad \text { Fostering social support } \\
\text { - } \quad \text { Optimising spousal relationships } \\
\text { - Increasing social awareness and acceptance } \\
\text { - } \quad \text { Specific recommendations based on values and beliefs } \\
\text { - Improvement of educational classes among all strata }\end{array}$ \\
\hline \multicolumn{2}{|l|}{ Psychological factors } \\
\hline 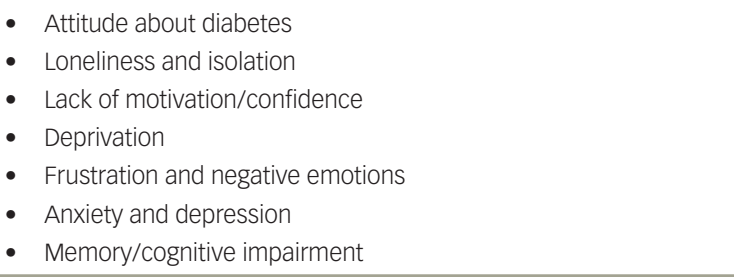 & $\begin{array}{l}\text { - } \quad \text { Improved quality of the patient-healthcare provider relationship } \\
\text { - } \text { - } \text { Minimising communication gaps } \\
\text { - } \quad \text { Behavioural interventions by enhancing supportive care }\end{array}$ \\
\hline \multicolumn{2}{|l|}{ Disease-related factors } \\
\hline $\begin{array}{l}\text { - } \text { Duration of disease } \\
\text { - Poor quality of life }\end{array}$ & $\begin{array}{l}\text { - } \text { Reducing the complexity of therapy } \\
\text { - Frequent/regular visits to healthcare professional }\end{array}$ \\
\hline
\end{tabular}

Figure 1: Approach of lifestyle interventions towards diabetes self-management

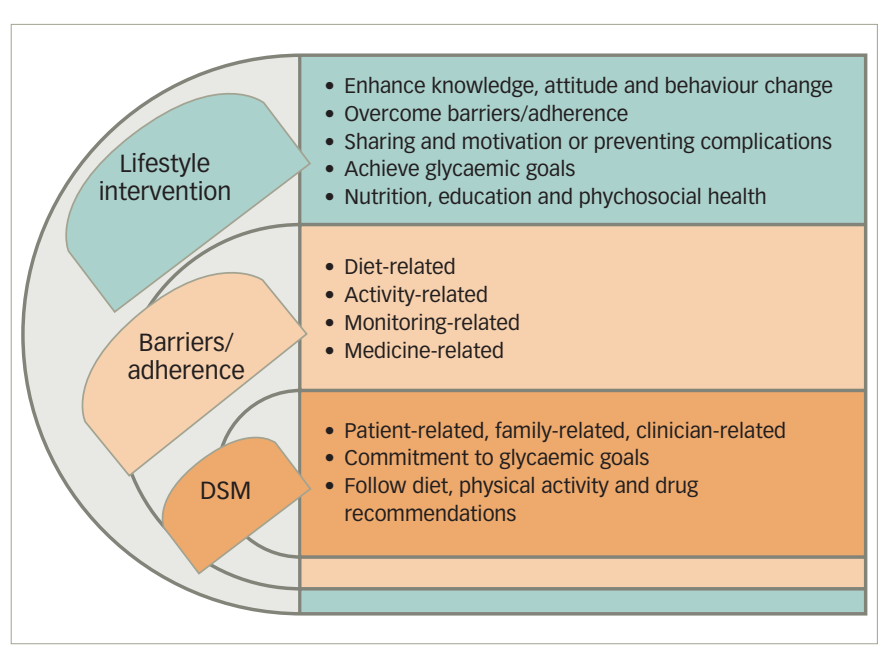

DSM = diabetes self-management

\section{Facilitating behaviours}

Positive family participation can encourage positive choices and will assist the patient to identify and overcome barriers to adherence. It can influence the patient's psychological wellbeing, informational and financial support, and give them the confidence to follow recommendations resulting in behaviour change to adopt healthy diet, lifestyle, exercise and timely medical regimen. Family participation can also lead to improvements in glycaemic control and diabetes selfmanagement via shared health-related activities or tasks together. ${ }^{38}$ It provides vigilance over changes in their clinical status or progressing complications. ${ }^{37}$ Finally, it enhances motivational skills for self-sufficiency, positive behaviours and independent attitudes towards disease..$^{39-41}$

\section{Negative behaviours}

Despite positive influence, family participation may also lead to obstructive behaviours, refusal to share the burden and limited family support or engagement. ${ }^{42}$ The practice of unhealthy dietary habits or lifestyle routines; lack of emotional, physical and financial support; and lack of empathy, awareness, understanding and knowledge can all contribute towards non-adherence to treatment and disease management. ${ }^{37,43,44}$

\section{Equivocal behaviours}

Family behaviours such as reminders for appointments with healthcare professionals, taking medications, exercising and maintaining a healthy diet can affect as both facilitator of or barrier to diabetes self-management. ${ }^{37,45}$

\section{Overcoming barriers}

Enhancing the facilitating behaviours, overcoming the negative behaviours and optimising or reinforcing the equivocal behaviours are major facets towards effective adherence and glycaemic achievement. ${ }^{46,47}$ Family members can encourage the patient, change the types of 
Table 2: Regimen-specific factors and their coping strategies

\begin{tabular}{|c|c|c|}
\hline \multirow[t]{6}{*}{ Diet-specific } & \multicolumn{2}{|l|}{ Personal factors } \\
\hline & $\begin{array}{l}\text { - } \quad \text { Inappropriate food consumed in family } \\
\text { - } \quad \text { Nobody to prepare food at regular times } \\
\text { - } \quad \text { Inadequate dietary intake } \\
\text { - } \quad \text { Inability to estimate portion size } \\
\text { - } \quad \text { Limited number of nutrition education sessions }\end{array}$ & $\begin{array}{l}\text { - } \\
\text { - Improvition counselling of family members } \\
\text { - Improving cooking skills } \\
\text { - } \quad \text { Access to nutrition education counselling }\end{array}$ \\
\hline & \multicolumn{2}{|l|}{ Social factors } \\
\hline & $\begin{array}{l}\text { - Overeating in response to people, place and emotions } \\
\text { - Food intake according to social context, time of day and place } \\
\text { - Social pressure }\end{array}$ & $\begin{array}{l}\text { - } \quad \text { Nutrition counselling of family members } \\
\text { - Improved nutrition education: patient and family members }\end{array}$ \\
\hline & \multicolumn{2}{|l|}{ Economic factors } \\
\hline & $\begin{array}{l}\text { - Increased availability of inexpensive fast foods high in fat, salt } \\
\text { and calories }\end{array}$ & - Easy availability and accessibility of diabetes-friendly products \\
\hline $\begin{array}{l}\text { Physical } \\
\text { activity-specific }\end{array}$ & $\begin{array}{l}\text { - } \quad \text { Associated complications } \\
\text { - } \quad \text { No access to materials and services needed } \\
\text { - } \quad \text { Sedentary lifestyle and monotony } \\
\text { - } \quad \text { Cultural difficulties for women }\end{array}$ & $\begin{array}{l}\text { - } \text { Promotion of individually tailored activities as per facilities available } \\
\text { - Exercise partner } \\
\text { - } \text { Exercise promotion programmes } \\
\text { - Awareness of benefits }\end{array}$ \\
\hline $\begin{array}{l}\text { BGM and } \\
\text { awareness-specific }\end{array}$ & $\begin{array}{l}\text { - Inability to use glucometer } \\
\text { - } \quad \text { Fear of pricking } \\
\text { - } \quad \text { Problems of mobility (old age) } \\
\text { - } \quad \text { Diabetic complications/comorbidities }\end{array}$ & - Enhanced social support \\
\hline $\begin{array}{l}\text { Medicine and } \\
\text { insulin-specific }\end{array}$ & $\begin{array}{l}\text { - Difficulty withdrawing the correct dose of insulin } \\
\text { - Fear of hypoglycaemia } \\
\text { - } \text { Complicated regimen } \\
\text { - } \text { Fear of side-effects } \\
\text { - } \quad \text { Poor health care system }\end{array}$ & $\begin{array}{l}\text { - Enhanced social support for shared responsibility, care and } \\
\text { understanding } \\
\text { - Improved healthcare facilities }\end{array}$ \\
\hline
\end{tabular}

$B G M=$ blood glucose monitoring

food prepared or consumed, can enjoy similar food in a comfortable environment, engage in physical activities, attend medical visits with the patient, reprioritise family finances, and make necessary lifestyle changes. All of these supportive actions will help towards improving dietary habits, adherence to the treatment, healthcare and the patient's clinical outcomes. ${ }^{40,48,49}$

\section{Diabetes control and festivals}

In India, numerous festivals are celebrated irrespective of caste, creed, age, and status, with different rituals irrespective of their health implications. People with diabetes are faced with multiple challenges related to diet, physical activity pattern, healthcareseeking behaviour and healthcare provision during such occasions. ${ }^{5}$ Family or spousal compliance towards the glycaemic management of their affected relative is paramount. The patient can be supported through practices such as healthy eating, medical nutrition therapy, avoiding excessive outdoor meals and erratic meal patterns, selfcare practices, blood glucose monitoring, physical activity, medication administration, and management of acute complications may; all of which will enhance compliance for the effective management of diabetes during the cultural and religious occasions. ${ }^{50}$

\section{Spousal participation in diabetes care plan}

A collaborative project from the UK Department of Health and the Royal Pharmaceutical Society of Great Britain in the mid-1990s yielded a better understanding of the factors affecting compliance, which conceptualised the evolution of "concordance". ${ }^{88,49}$ With a shift from compliance to concordance in diabetes and its complications, spousal concordance is defined by researchers as "shared similarity of habits, behaviours and health statuses among the partners or spouses" .51,52
In this view, the concept of dyadic coping refers to the collective efforts of the partners to manage stress, develop problem-focused or emotionfocused strategies for better glycaemic control and improved quality of life together (Figure 2). It leads to the emergence of empirical and theoretical evidence of illness-specific spousal support in better health outcomes of chronic illness, with assumption of sustained effects with regards to the patient's adherence to diet and exercise programmes. Spousal support is associated with better patient diabetes self-efficacy, both with regards to diet and exercise. ${ }^{53,54}$

Some of the explored factors with regards to better glycaemic control include age, family environment, emotional support, social status, positive relationship, shared expectations, motivation and responsibility, effective communication, sense of responsibility and common family eating patterns. ${ }^{55-57} \mathrm{~A}$ sense of coherence also seems to be established among older populations. ${ }^{58}$ Table 3 highlights the domains of spousal concordance in diabetes. ${ }^{44,54,57,59-64}$

A systematic review and meta-analysis conducted in 2014 has shown, with a pooled estimate, that partners have a $26 \%$ increased risk of developing diabetes which highlights the importance of collective efforts to optimise healthy eating and physical activity patterns..$^{65}$ An article published by Wang et al., reported a significantly higher risk $(5.19 \%, p<0.0001)$ of diabetes concordance in couples, associated with old age, middle levels of urbanisation, and high comorbidities (all $\mathrm{p}<0.05$ ). ${ }^{66} \mathrm{~A}$ systematic review published in 2017 by Dimova et al. identified shared risk of diabetes among relatives of people with T2DM. ${ }^{62}$ It examined various randomised controlled trials to identify behaviour change strategies focussed on diet and physical activity to delay or prevent T2DM among the relatives or partners of people with T2DM to enhance effectiveness in their own health. It found sustained 
Table 3: Domains of spousal concordance in diabetes

\begin{tabular}{|c|c|c|}
\hline Study and year & Domains & Effects \\
\hline Johnson et al., $2015^{44}$ & Spousal overprotection & $\begin{array}{l}\text { - It is associated with poorer dietary adherence and increased diabetes distress, having an } \\
\text { adverse impact on glycaemic control }\end{array}$ \\
\hline Pereira et al., $2015^{54}$ & $\begin{array}{l}\text { Patients' and partners' variables regarding } \\
\text { adherence to self-care }\end{array}$ & $\begin{array}{l}\text { - Adherence to diet is positively influenced by patient dyadic adjustment and positive } \\
\text { - } \text { support; while negatively influenced by partner depression and negative support } \\
\text { partner anxiety } \\
\text { - } \text { Adherence to glucose monitoring is affected by partner positive support } \\
\text { - Positive partner support moderates the relationship between family stress and dyadic } \\
\text { adjustment }\end{array}$ \\
\hline Henry et al., $2013^{59}$ & $\begin{array}{l}\text { Spousal tempting and undermining of the } \\
\text { diabetic regimen }\end{array}$ & $\begin{array}{l}\text { - Spousal tempting is associated with worse dietary adherence, and spousal disregard of } \\
\text { diabetes is associated worse non-dietary adherence } \\
\text { - Spousal undermining is relatively rare and is related to worse adherence and worse } \\
\text { glycaemic control }\end{array}$ \\
\hline Johnson et al., $2013^{60}$ & Diabetes efficacy & $\begin{array}{l}\text { - Intervention and assessment efforts improving diabetes outcomes are influenced by } \\
\text { targeting the patient's dynamics in their intimate relationship and eliciting the spouse's } \\
\text { beliefs about type } 2 \text { diabetes, in addition to the patient's beliefs }\end{array}$ \\
\hline Franks et al., $2012^{61}$ & $\begin{array}{l}\text { Association of diet-related interactions with } \\
\text { partner's adjustment to the illness }\end{array}$ & $\begin{array}{l}\text { - Involvement of partners in illness management with their partners being associated with } \\
\text { their own diabetes distress and with that of their ill partners }\end{array}$ \\
\hline August et al., $2011^{57}$ & Social control & $\begin{array}{l}\text { - Partners experience greater burden, particularly when their partners exhibit poor dietary } \\
\text { adherence and react negatively to their spouse's involvement }\end{array}$ \\
\hline Stephens et al., $2010^{62}$ & Spousal control strategies & $\begin{array}{l}\text { - Partner warning and less coercive influence attempts are associated with poorer } \\
\text { adherence; positive encouragement is associated with better adherence }\end{array}$ \\
\hline Beverly et al., $2008^{63}$ & Food-related behaviour change & $\begin{array}{l}\text { - The partner relationship can influence food-related behaviour by control over food, } \\
\text { dietary competence, commitment to support, spousal communication and coping with } \\
\text { diabetes }\end{array}$ \\
\hline Garay-Sevilla et al., $1995^{64}$ & $\begin{array}{l}\text { Adherence to diet and medication, } \\
\text { knowledge on diabetes, social support, } \\
\text { structure and functioning }\end{array}$ & $\begin{array}{l}\text { - Adherence to treatment is associated with social support } \\
\text { - Aspects such as the age of the partner and the control of behaviour are also associated } \\
\text { with treatment compliance }\end{array}$ \\
\hline
\end{tabular}

Table 4: Spousal interventional studies among people with diabetes

\begin{tabular}{|c|c|c|c|c|c|}
\hline Study and year & Sample size & Domains/parameters & $\begin{array}{l}\text { Interventions, } \\
\text { scales or tools }\end{array}$ & Results & Conclusion \\
\hline Trief et al., 2016 68 & 280 couples & $\begin{array}{l}\text { Glycaemic control } \\
\text { and secondary } \\
\text { outcomes: BMl, waist } \\
\text { circumference, blood } \\
\text { pressure, depressive } \\
\text { symptoms, diabetes } \\
\text { self-efficacy, and } \\
\text { diabetes distress }\end{array}$ & $\begin{array}{l}\text { Four-month } \\
\text { intervention } \\
\text { among three } \\
\text { arms: } C C \mathrm{n}=104 \text {, } \\
\text { IC } n=94 ; \mathrm{DE} \\
\mathrm{n}=82\end{array}$ & $\begin{array}{l}\text { - Significant } \mathrm{HBA} 1 \mathrm{C} \text { reductions for all ( } 12 \\
\text { months: CC }-0.47 \% \text {, IC }-0.52 \%, \mathrm{DE}-0.57 \% \text { ) } \\
\text { improvement (4 months }-0.354, \mathrm{p}=0.009 ; 8 \\
\text { months }-0.393, \mathrm{p}=0.027 ; 12 \text { months }-0.474 \text {, } \\
\mathrm{p}=0.021 \text { ) with significant } \mathrm{CC} \text { reductions at all } \\
\text { follow ups ( } \mathrm{p}<0.001 \text { ) } \\
\text { - The IC arm showed greater blood pressure } \\
\text { improvement while results for secondary } \\
\text { psychosocial outcomes favoured the CC arm }\end{array}$ & $\begin{array}{l}\text { A collaborative couples } \\
\text { intervention resulted } \\
\text { in significant, lasting } \\
\text { improvements in HbA1C } \\
\text { levels, obesity measures, } \\
\text { and some psychosocial } \\
\text { outcomes }\end{array}$ \\
\hline Trief et al., $2011^{69}$ & $\begin{array}{l}\text { Couples }(n=44) \text {, } \\
\text { in which one } \\
\text { partner had } \\
\text { T2DM }\end{array}$ & $\begin{array}{l}\text { Telephone goal-setting, } \\
\text { dietary behaviour } \\
\text { change, and a focus on } \\
\text { emotions }\end{array}$ & $\begin{array}{l}\text { Couple } \\
\text { intervention, } \\
\text { individual } \\
\text { intervention, } \\
\text { individual DE }\end{array}$ & $\begin{array}{l}\text { - Mixed-model regression analyses found } \\
\text { statistically significant treatment effects for } \\
\text { total cholesterol }\end{array}$ & $\begin{array}{l}\text { DE resulted in improved } \\
\text { blood glucose control }\end{array}$ \\
\hline Gilden et al., $1989^{70}$ & $\begin{array}{l}\text { Older male } \\
\text { patients (aged } \\
65-82 \text { years) and } \\
\text { their partners }\end{array}$ & Scored questionnaires & $\begin{array}{l}\text { Six-week DE } \\
\text { programme }\end{array}$ & $\begin{array}{l}\text { - Increased knowledge of diabetes }(p<0.05) \text {; } \\
\text { reduction in stress correlated with increased } \\
\text { knowledge }(r=0.9 ; p<0.05) \text { and improved } \\
\text { diet-related QoL }(r=0.7 ; p<0.02) \\
\text { - Decreased stress, enhanced QOL }(p<0.01) \text {, } \\
\text { greater improvement in knowledge }(p<0.02) \text {, } \\
\text { increase in family involvement }(p<0.05) \\
\text { - Improvement in metabolic control of } \\
\text { diabetes }(p<0.001)\end{array}$ & $\begin{array}{l}\text { DE intervention is effective } \\
\text { for both patients and their } \\
\text { partners }\end{array}$ \\
\hline
\end{tabular}

$B M I=$ body mass index; $C C=$ couples call; $D E=$ diabetes education; $H D A 1 C=$ glycated haemoglobin; IC = individual calls; QoL = quality of life; $T 2 D M=$ type 2 diabetes mellitus; WC $=$ waist circumference 
modifications in participant's behaviour, which resulted in decreased daily calorie intake, increased physical activity, weight loss, decreased waist circumference and sagittal diameter, with significant correlations between the behaviour of patients and their partners. ${ }^{67}$

Only a few interventional studies have been conducted so far to explore the direct influence of partners of diabetic partners on lifestyle interventions for the improvement of adherence to the treatment (Table 4). ${ }^{68-70}$ Spousal involvement has been associated with improved support or care in chronic pain outcomes such as pain severity, pain behaviours and psychological distress. ${ }^{10,71}$ This may be especially relevant in patients with painful diabetic neuropathy or musculoskeletal complications of diabetes like frozen shoulder among others. Spousal participation can be a potential source of health-enhancing support (Figure 1). $23,2,6,31,3,3,38,4,1,49,51,68$

\section{Role of partner and family support - evidence from the clinical trials}

The Look AHEAD (Action for Health in Diabetes) trial is the longest trial published, to date ( 8 years' data), to evaluate the impact of intensive lifestyle interventions on weight loss, glycaemic control and cardiovascular outcomes in diabetes. ${ }^{72}$ Weight loss in Look AHEAD trial was $-8.6 \%$ at 1 -year follow-up and continued to be an impressive $-4.7 \%$ at 8 years of follow-up. ${ }^{72}$ Unlike previous studies, the Look AHEAD trial did not involve intensive one-to-one sessions with dieticians/diabetes educators. Instead, in this study a group-counselling approach was used. A total of 19 group-counselling sessions took place over a period of 8 years where the patient and family members/ partners were given general advice on therapeutic lifestyle interventions. ${ }^{72,73}$ The study's "toolbox" technique of group counselling, motivational interviews, improving selfimage among family and friends was found to be highly effective. It was not only found to be cost effective, but also as efficacious in regards to weight loss and glycaemic control, which has been traditionally used in diabetes management. ${ }^{73}$ Hence the Look AHEAD study highlighted the importance of the positive impact of lifestyle changes in the entire family/community group rather than the individual alone.

The DiRECT (Dlabetes REmission Clinical Trial) study has further highlighted the importance of weight loss in diabetes management. ${ }^{74}$ It demonstrated that in overweight and obese patients with T2DM of up to 6 years of disease duration and on multiple oral anti-diabetes medications, aggressive weight loss strategies with very low-calorie diet can result in remission of diabetes - defined as stoppage of all anti-diabetes medications and $\mathrm{HbA} 1 \mathrm{C}<6.5 \%$ for at least 2 months. ${ }^{74}$ The greater the weight loss, the better were the chances of diabetes remission as evidenced by $7 \%$ remission with 0-5 kg weight loss, 34\% remission with 5-10 kg loss, 57\% remission with 10-15 kg loss, and 86\% remission with $>15 \mathrm{~kg}$ weight loss. ${ }^{74}$

\section{Future implications}

There is a paucity of data on the effects of spousal participation on health, glycaemic control, diabetes management and quality of life in lifestyle intervention studies and therefore more research is needed in
Figure 2: Challenges in diabetes self-management and effect of social support

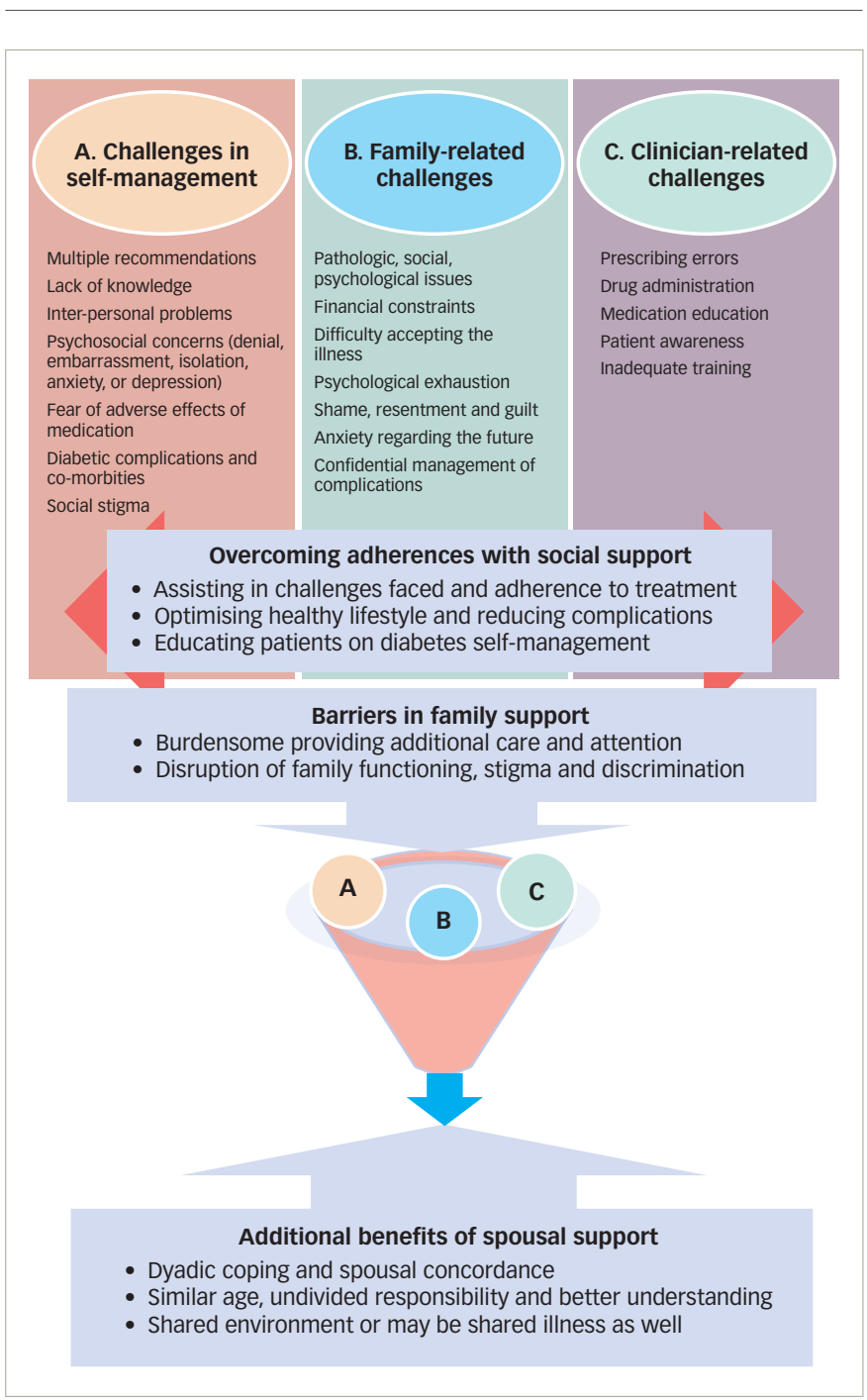

this area. Further interventional studies evaluating the role of partner and family support in weight loss and diabetes management are urgently warranted.

\section{Conclusion}

Social support from family members and spouses/partners is beneficial to improve adherence to the lifestyle interventions and diabetes selfmanagement required to achieve optimum glycaemic control and prevent or delay associated complications. There is paucity of data regarding the mechanism behind such support. Clinical and research interventions should consider implementing dyadic educational (e.g. nutrition, exercise, medication adherence) and motivational skills training (e.g. problem solving, emotional expressiveness training) to facilitate and optimise spousal support resources. $\square$
1. IDF Diabetes Atlas - 8th Edition. 2017. Available at: www. diabetesatlas.org/resources/2017-atlas.html (accessed 24 August 2018)

2. Dutta D, Mukhopadhyay S. Intervening at prediabetes stage is critical to controlling the diabetes epidemic among Asian Indians. Indian J Med Res. 2016;143:23-6.

3. Dutta D, Mukhopadhyay S. Comment on Anjana et al. Incidence of diabetes and prediabetes and predictors of progression among Asian Indians: 10-year follow-up of the chennai urban rural epidemiology study (CURES). Diabetes Care 2015;38:14411448. Diabetes Care. 2015
0908 [Epub ahead of print].
4. NDTV, World Diabetes Day 2017: Number of Diabetics to Double In India by 2023, 2017. Available at: www.ndtv.com/food/worlddiabetes-day-2017-number-of-diabetics-to-double-in-indiaby-2023-1775180 (accessed 24 August 2018).

5. Gupta L, Khandelwal D, Singla R, et al. Pragmatic dietary advice for diabetes during Navratris. Indian J Endocrinol Metab. 2017;21:231-7.

6. Delamater AM. Improving patient adherence. Clinical Diabetes. 2006;24:71-7.

7. Miller TA, Dimatteo MR. Importance of family/social support and impact on adherence to diabetic therapy. Diabetes Metab syndr Obes. 2013;6:421-6.
8. Chesla CA, Fisher L, Skaff MM, et al. Family predictors of disease management over one year in Latino and European American patients with type 2 diabetes. Fam Process. 2003;42:375-90.

9. Fisher L, Weihs KL. Can addressing family relationships improve outcomes in chronic disease? Report of the National Working Group on family-based interventions in chronic disease. J Fam Pract. 2000;49:561-6.

10. Seidel AJ, Franks MM, Stephens MA, Rook KS. Spouse contro and type 2 diabetes management: moderating effects of dyadic expectations for spouse involvement. Fam Relat. 2012;61:698-709. 
11. Black DR, Gleser $\sqcup$, Kooyers KJ. A meta-analytic evaluation of couples weight-loss programs. Health Psychol. 1990;9:330-47.

12. Huang XL, Pan JH, Chen D, et al. Efficacy of lifestyle interventions in patients with type 2 diabetes: A systematic review and meta-analysis. Eur I Intern Med. 2016:27:37-47.

13. Cezaretto $A$, Ferreira $S R$, Sharma $S$, et al. Impact of lifestyle interventions on depressive symptoms in individuals at-risk of, or with, type 2 diabetes mellitus: A systematic review and meta-analysis of randomized controlled trials. Nutr Metab Cardiovasc Dis. 2016;26:649-62.

14. Htoo ZW, Hsu WW, Rosenkranz R. Systematic review and metaanalysis: Is lifestyle modification effective for glycemic control among adults with type II diabetes in Southeast Asia? Diabetes Res Clin Pract. 2016;122:148-53.

15. Norris SL, Lau J, Smith SJ, et al. Self-management education for adults with type 2 diabetes: a meta-analysis of the effect on glycemic control. Diabetes Care. 2002;25:1159-71.

16. Schellenberg ES, Dryden DM, Vandermeer B, et al. Lifestyle interventions for patients with and at risk for type 2 diabetes: a systematic review and meta-analysis. Ann Intern Med. 2013;159:543-51.

17. Vermeire E, Wens I, Van Royen P, et al. Interventions for improving adherence to treatment recommendations in people with type 2 diabetes mellitus. Cochrane Database Syst Rev. 2005; (2):CD003638

18. Mumu SJ, Saleh F, Ara F, et al. Non-adherence to life-style modification and its factors among type 2 diabetic patients. Indian J Public Health. 2014:58:40-4.

19. Khunti K, Ceriello A, $\operatorname{Cos} X$, De Block C. Achievement of guideline targets for blood pressure, lipid, and glycaemic control in type 2 diabetes: A meta-analysis. Diabetes Res Clin Pract. 2018;137:137-48.

20. Amaltinga APM. Non adherence to diabetic medication among diabetic patients, a case study of Dormaa Hospital

Ghana. Scicnce Jount of Public Health. 2017;5:88-97. 21. Debussche $X$. Is adherence a relevant issue in the self-
management education of diabetes? A mixed narrative review.

22. Polonsky WH, Henry RR. Poor medication adherence in type 2 diabetes: recognizing the scope of the problem and its key contributors. Patient Prefer Adherence. 2016;10:1299-307.

23. Ahola AJ, Groop PH. Barriers to self-management of diabetes Diabet Med. 2013;30:413-20.

24. Vermeire E, Hearnshaw H, Rätsep A, et al. Obstacles to adherence in living with type-2 diabetes: an international qualitative study using meta-ethnography (EUROBSTACLE). Prim Care Diabetes. 2007:125-33.

25. Hilliard ME, Powell PW, Anderson BJ. Evidence-based behaviora interventions to promote diabetes management in children, adolescents, and families. Am Psychol. 2016;71:590-601.

26. Sohal T, Sohal P. King-Shier KM, Khan NA. Barriers and facilitators for type-2 diabetes management in South Asians: a facilitators for type-2 diabetes management in South

27. Venditti EM, Tan K, Chang N, et al. TODAY Study Group. Barriers and strategies for oral medication adherence among children and adolescents with Type 2 diabetes. Diabetes Res Clin Pract. 2018;139:24-31

28. Trevisan DD, São-João TM, Cornélio ME, et al. A randomized controlled trial on the effect of behavioral strategies for adherence to oral antidiabetic drugs: study protocol. Contemp Nurse. 2017;53:658-68.

29. Jaworski M, Panczyk M, Cedro M, Kucharska A. Adherence to dietary recommendations in diabetes mellitus: disease acceptance as a potential mediator. Patient Prefer Adherence. 2018;12:163-74

30. Kavitha S, Nalini GK, Suresh RM, et al. Treatment adherence and factors contributing to non adherence among type 2 diabetes mellitus patients in a tertiary care hospital: a cross sectional study. Int J Basic Clin Pharmacol. 2017:6:689-94.

31. Pereira MG, Pedras S, Ferreira G, Machado JC. Family and couple variables regarding adherence in type 2 diabetes patients in the initial stages of the disease. J Marital Fam Ther. 2019;45:134-48.
32. Van Buren DJ, Wiffley DE, Marcus MD, et al. TODAY Study Group Depressive symptoms and glycemic control in youth with type 2 diabetes participating in the TODAY clinical trial. Diabetes Res Clin Pract. 2018:135:85-7.

33. Seamark D, Gabriel L. Barriers to support: a qualitative exploration into the help-seeking and avoidance factors of young adults. Br J Guid Counc. 2018;46:120-31.

34. Pereira MG, Ferreira G, Machado JC. Spousal support and satisfaction with healthcare services as moderators between psychological morbidity and adherence to diet in type 2 diabetes patients. Health Behav Policy Rev. 2014;1:278-89.

35. Denham SA. Family routines: a structural perspective for viewing family health. Adv Nurs Sci. 2002;24:60-74.

36. Grabowski D, Andersen $\mathrm{TH}$, Varming A, et al. Involvement of family members in life with type 2 diabetes: Six interconnected problem domains of significance for family health identity and healthcare authenticity. SAGE Open Med. 2017:5:2050312117728654.

37. Vongmany J, Luckett T, Lam L, Phillips JL. Family behaviours that have an impact on the self-management activities of adults living with Type 2 diabetes: a systematic review and metasynthesis. Diabet Med. 2018;35:184-94.

38. Baig AA, Benitez A, Quinn MT, Burnet DL. Family interventions to improve diabetes outcomes for adults. Ann N Y Acad SCi. 2015;1353:89-112

39. Markle-Reid M, Ploeg J, Fraser KD, et al. The ACHRU-CPP versus usual care for older adults with type-2 diabetes and multiple chronic conditions and their family caregivers: study protocol for a randomized controlled trial. Trials. 2017;18:55

40. Wichit N, Mnatzaganian G, Courtney M, et al. Randomized controlled trial of a family-oriented self-management program to improve self-efficacy, glycemic control and quality of life among Thai individuals with type 2 diabetes. Diabetes Res Clin Pract. 2017:123:37-48.

41. Pamungkas RA, Chamroonsawasdi $K$, Vatanasomboon $P$. A systematic review: family support integrated with diabetes self-management among uncontrolled type II diabetes mellitus patients. Behav Sci (Basel). 2017;7:62.

42. Bennich BB, Røder ME, Overgaard D, et al. Supportive and non-supportive interactions in families with a type 2 diabetes patient: an integrative review. Diabetol Metab Syndr. 2017; 9:57.

43. Mayberry LS, Osborn CY. Family support, medication adherence, and glycemic control among adults with type 2 diabetes. Diabetes Care. 2012;35:1239-45

44. Johnson MD, Anderson JR, Walker A, et al. Spousal overprotection is indirectly associated with poorer dietary adherence for patients with type 2 diabetes via diabetes distress when active engagement is low. Br J Health Psychol. 2015;20:360-73.

45. Keogh $\mathrm{KM}$, White P, Smith SM, et al. Changing illnes perceptions in patients with poorly controlled type 2 diabetes, a randomised controlled trial of a family-based intervention: protocol and pilot study. BMC Fam Pract. 2007;8:36.

46. Vissenberg C, Nierkens V, Uitewaal PJM, et al. Development of the social network-based intervention "powerful togethe with diabetes" using intervention mapping. Front Public Health. 2017;5:334.

47. Samuel-Hodge CD, Cene CW, Corsino L, et al. Family diabetes matters: a view from the other side. I Gen Intern Med. 2013;28:428-35

48. TODAY Study Group. Design of a family-based lifestyle intervention for youth with type 2 diabetes: the TODAY study. Int J Obes (Lond). 2010;34:217-26.

49. Ahmed Z, Yeasmeen F. Active family participation in diabetes self-care: a commentery. Diabetes Management. 2016;6:104-7.

50. Dutta D, K Biswas, M Sharma, et al. Managing diabetes during Navratris with special focus on Durga pujas. Journal of Social Health \& Diabetes. 2015:3:84-8.

51. Chatterjee IS. From compliance to concordance in diabetes. J Med Ethics. 2006;32:507-10

52. Al-Sharbatti SS, Abed YI, Al-Heety LM, Basha SA. Spousal concordance of diabetes mellitus among women in
Ajman, United Arab Emirates. Sultan Qaboos Univ Med J. 2016:16:e197-202.

53. Lewis MA, MCBride CM, Pollak KI, et al. Understanding health behavior change among couples: an interdependence and communal coping approach. Soc Sci Med. 2006;62:1369-80

54. Pereira MG, Costa V O Oliveira D, et al. Patients' and spouses' contribution toward adherence to self-care behaviors in type 2 diabetes. Res Theory Nurs Pract. 2015;29:276-96.

55. Lin EH, Katon W, Von Korff M, et al. Relationship of depression and diabetes self-care, medication adherence, and preventive care. Diabetes Care. 2004;27:2154-60

56. Trief PM, Sandberg J, Greenberg RP, et al. Describing support: A qualitative study of couples living with diabetes. Families, Systems, \& Health. 2003;21:57-67.

57. August KJ, Rook KS, Stephens MA, Franks MM. Are spouses of chronically ill partners burdened by exerting health-related social control? J Health Psychol. 2011;16:1109-19.

58. Potier F, Degryse JM, Henrard S, et al. A high sense of coherence protects from the burden of caregiving in older coherence protects from the burden of caregiving in older

59. Henry SL, Rook KS, Stephens MA, Franks MM. Spousal undermining of older diabetic patients' disease management. J Health Psychol. 2013;18:1550-61.

60. Johnson MD, Anderson JR, Walker A, et al. Common dyadic coping is indirectly related to dietary and exercise adherence via patient and partner diabetes efficacy. J Fam Psychol. 2013;27:722-30.

61. Franks MM, Sahin ZS, Seidel AJ. Table for two: diabetes distress and diet-related interactions of married patients with diabetes and their spouses. Fam Syst Health. 2012;30:154-65.

62. Stephens MA, Rook KS, Franks MM, et al. Spouses use of social control to improve diabetic patients' dietary adherence. Fam Syst Health. 2010;28:199-208

63. Beverly EA, Miller CK, Wray LA. Spousal support and foodrelated behavior change in middle-aged and older adults living with type 2 diabetes. Health Educ Behav. 2008;35:707-20.

64. Garay-Sevilla ME, Nava LE Malacara JM, et al. Adherence to treatment and social support in patients with non-insulin dependent diabetes mellitus. J Diabetes Complications. 1995;9:81-6.

65. Leong A, Rahme E, Dasgupta K. Spousal diabetes as a diabetes risk factor: a systematic review and meta-analysis. BMC Med. 2014;12:12

66. Wang JY, Liu CS, Lung $\mathrm{CH}$, et al. Investigating spousal concordance of diabetes through statistical analysis and data mining. PLoS One. 2017;12:e0183413.

67. Dimova ED, Mohan ARM, Swanson V, Evans JMM. Interventions for prevention of type 2 diabetes in relatives: A systematic review. Prim Care Diabetes. 2017:11:313-26.

68. Trief PM, Fisher L, Sandberg J, et al. Health and psychosocial outcomes of a telephonic couples behavior change intervention in patients with poorly controlled type 2 diabetes: a randomized clinical trial. Diabetes Care. 2016;39:2165-73.

69. Trief P, Sandberg JG, Ploutz-Snyder R, et al. Promoting couples collaboration in type 2 diabetes: the diabetes support project pilot data. Fam Syst Health. 2011;29:253-61.

70. Gilden JL, Hendryx M, Casia C, Singh SP. The effectiveness of diabetes education programs for older patients and their spouses. J Am Geriatr SOC. 1989;37:1023-30.

71. Leonard MT, Cano A, Johansen AB. Chronic pain in a couples context: a review and integration of theoretical models and empirical evidence. J Pain. 2006;7:377-90.

72. Wadden TA, Bantle JP, Blackburn GL, et al. Look AHEAD Research Group. Eight-year weight losses with an intensive lifestyle intervention: the look AHEAD study. Obesity (Silver Spring). 2014:22:5-13.

73. Salvia MG. The look AHEAD trial: translating lessons learned into clinical practice and further study. Diabetes Spectr. 2017;30:166-170

74. Lean ME, Leslie WS, Barnes AC, et al. Primary care-led weight management for remission of type 2 diabetes (DiRECT): an open-label, cluster-randomised trial. Lancet. 2018;391: $541-51$. 